\title{
EVALUATING IMAGERY-DERIVED BATHYMETRY OF SEABED TOPOGRAPHY TO SUPPORT MARINE CADASTRE
}

\author{
Kelvin Kang Wee Tang ${ }^{1,2}$, Mohd Razali Mahmud ${ }^{1}$, Alhaji Hussaini ${ }^{1}$ and Auwal Garba Abubakar ${ }^{1}$ \\ ${ }^{1}$ Faculty of Built Environment and Surveying, Universiti Teknologi Malaysia, 81310 Johor Bahru, Malaysia \\ tkwkelvin2@live.utm.my \\ ${ }^{2}$ Department of Survey and Mapping Malaysia, 50578 Kuala Lumpur, Malaysia
}

KEY WORDS: Imagery-Derived Bathymetry, Seabed Topographic Mapping, Marine Cadastre

\begin{abstract}
:
The Department of Survey and Mapping Malaysia has introduced marine cadastre system to register the rights, other valid interests therein and ownership of spatially determined parcels in the context of the marine environment yet the implementation of the system is still at the rudimentary stage. One of the big issues here is gathering land-to-seabed data to create a seamless topographic base map to support its marine cadastre project. Seabed bathymetric mapping in coastal zone is one of the major components to support marine cadastre. In the past, accurate bathymetric measurements can be a very laborious task in hydrographic surveying. Traditional vesselbased acoustic soundings require a lot of time, operation cost and others. Today, human's ingenuity to yield bathymetric depths from multispectral images as an alternative source to chart the seabed topography has brought in new revolution to hydrography. The paper is initiated for evaluating water depth determination by using imagery-derived bathymetry technique and check its correlation with in-situ bathymetry depths. In the course of experiment, it demonstrates a good correlation between the imagery-derived bathymetric depths and the in-situ bathymetric depths, and majority of the derived depths have passed the minimum requirement of the IHO S-44 survey standard. The result also shows that these empirical models deliver promising outcome which can be use over the turbid environment setting. Hence, imagery-derived bathymetry approach can be an efficient and repeatable way to derive the seabed topography over a huge segment of coastal region. This study also suggests that imagery-derived bathymetry approach can be recognised as an aid in seabed topographic mapping to support marine cadastre initiative.
\end{abstract}

\section{INTRODUCTION}

In Malaysia, the hasty urbanization activities run not limited in coastal land, but also moving off the foreshore region. This massive land development has changed of patterns in property ownerships' management. Apparently, Department of Survey and Mapping Malaysia (DSMM) has introduced marine cadastre system to register the rights, other valid interests therein and ownership of spatially determined parcels in the context of the marine environment yet the implementation of the marine cadastre system is still at the rudimentary stage and many technical and legal issues need to be determined (Abdullah et al., 2014; Nazirah \& Abdullah, 2014). One of the big issues here is gathering land-to-seabed data to create a seamless topographic base map to support DSMM's marine cadastre project (Azhari et al., 2017). The idea of having a Marine Geodetic Database (MGDB) for the development of a comprehensive Marine Spatial Data Infrastructure (MSDI) to facilitate security, marine cadastre, coastal geographical information system (GIS), economic development and environmental protection activities.

Apparently, more than sixty percent of the world's population today are living at the vulnerable coastal zone. Variations in the extremely versatile and dynamic coastal area can be associated to manmade activities as well as natural morphology alteration which happen either gradually or out of the sudden. Significant changes within a short period may not practical to be attempted using timely consuming ship-based sounding systems. Much of the coastal and shallow water zone remains unmapped, indeed poorly understood. In short, most of the navigation charts and topographic maps at those area is outdated and may not showing the possible hazards to the users.
Today, the ability of electromagnetic spectrum to penetrate water column has brought in new revolution the hydrographic surveying. The fundamental principle of extracting water depth information for bathymetric mapping using optical remote sensing data, a range of visible electromagnetic wavelengths (EMR) which can penetrate the water column in various degrees. This radiometric technique is first addressed by Lyzenga (1978) and further explored by Benny and Dawson (1983), Spitzer and Driks (1987), Jupp (1988), Philpot (1989), Bierwirth (1993), Maritorena et al. (1994), Dierssen et al. (2003), Stumpf et al. (2003) and updated by Lyzenga et al. (2006). These empirical, analytical and semi-analytical bathymetry retrieval methods are reportedly practical in clear coastal and shallow water for bathymetric mapping (Pacheco et al., 2014; Jawak, Vadlamani, \& Luis, 2015; Pe'eri et al., 2013; Jégat et al., 2016; Mavraeidopoulos et al. 2017).

For instance, the imagery-derived bathymetry technique has becoming popular and being employed as an alternative data acquisition technique over the shallow water and turbid tropical settings (Branmante et al., 2013, Tang \& Pradhan, 2015; Said et $a l .$, 2017). The main reason is because this flaxible technique does not require extensive amount of time, money and effort due to its vast spatial coverage (Gao, 2009; Jawak, Vadlamani, \& Luis, 2015). This present study takes the initiative to evaluate the imagery-derived bathymetry's accuracy regarding the total vertical uncertainty (TVU) which are stipulated in International Hydrographic Organisation (IHO) Standards for Hydrographic Surveys Special Publication No.44 (S-44). Hence, the ultimate aim of this study is evaluating data quality of imagery-derived bathymetry mapping and its usability as an aid to support marine cadastre initiative. 


\section{DATA AND METHODOLOGY}

This section outlines the characteristics of the study area and imagery-derived bathymetry approaches being adopted here to estimate the bathymetric depths from multispectral images. It briefly reviews on the selected imagery-derived bathymetry models, characteristics of the multispectral images, auxiliary data and image processing software as well as accuracy assessment being applied in this study.

\subsection{Study Area}

Malaysia is recognized as a maritime country with a total land mass of approximately 329,000 square kilometres, including 827 islands and 273 geographical entities within its 574,400 square kilometres marine jurisdiction. Its 4,809 kilometres coastal belt varies from scenic bays flanked by rocky headlands to shallow mud flats lined with mangrove forests rich in biodiversity.

The authors conducted this study in southwest of Johor State, Malaysia, focused on a relatively small region. It made an attempt to determine the bathymetric depths of the study area, focusing at the shallow and near shore coastal waters as shown in Figure 1. It attempts to examine estimate the imagery-derived bathymetric depths lies between latitudes of $1^{\circ} 18^{\prime} \mathrm{N}$ to $1^{\circ} 21^{\prime} \mathrm{N}$ and longitudes of $103^{\circ} 34^{\prime} \mathrm{E}$ to $103^{\circ} 38^{\prime} \mathrm{E}$. Generally, the water bordering the study area is high turbidity which is also capable to represent majority of the west coast areas in Peninsular Malaysia. Typically, most of the swampy shoreface is fronted by flat slopes with highly turbid suspended sediments.

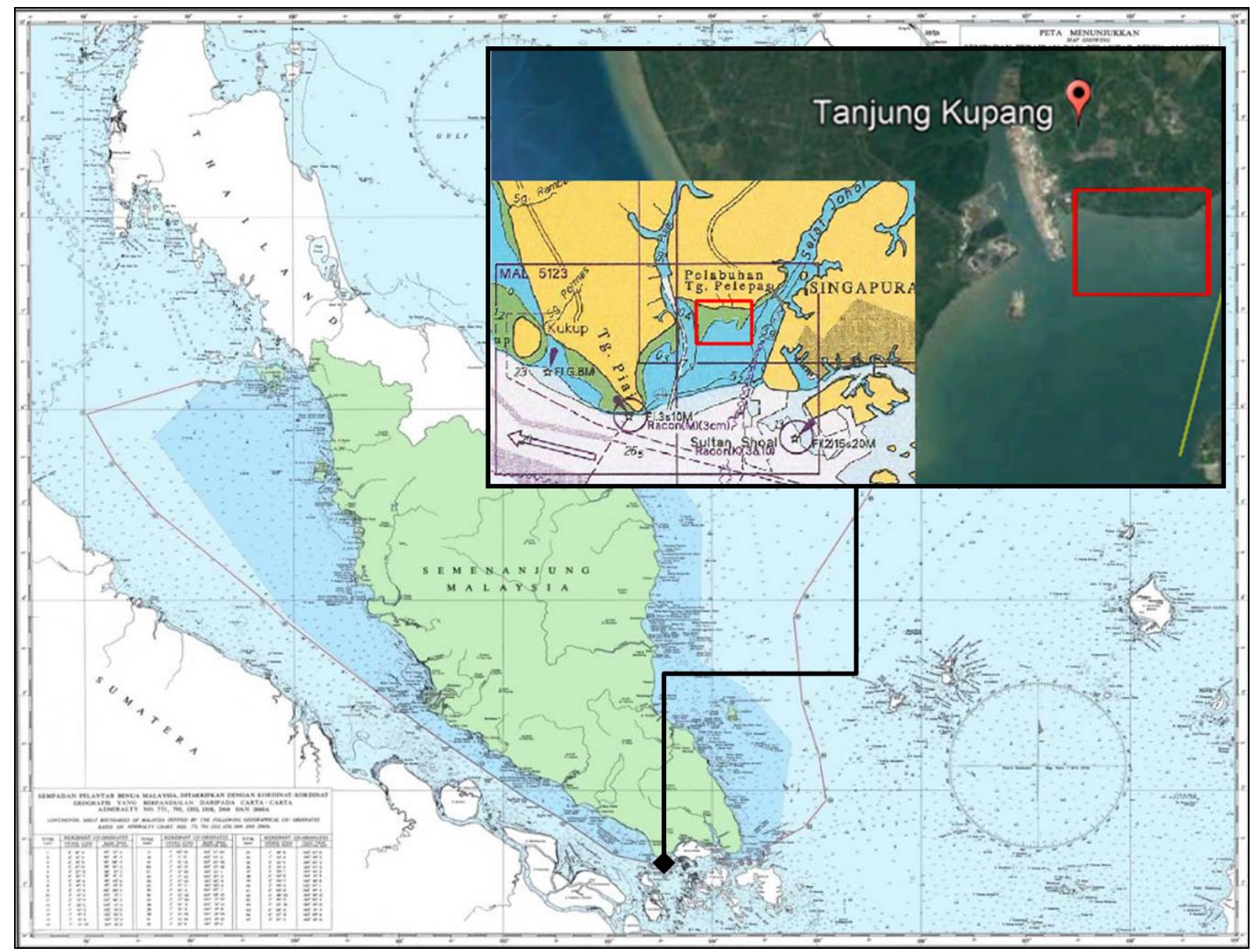

Figure 1. Coverage of the study area over the southwest of Johor state, Malaysia.

\subsection{Methodology}

This study incorporated the space-borne remote sensing and geographical information system (GIS) techniques to extract bathymetric depths from multispectral images. The overall research methodology and processing stages such image preprocessing, image processing or bathymetric model construction as well as data verification to assess the data accuracy is shown in Figure 2.

Selection of imagery-derived bathymetry mapping was based on the condition of the satellite images, significantly spectral coverage, spectrum range and ground resolution. Prior attempting to the image processing, pre-processing process like radiometric correction and atmospheric correction were applied to remove the atmospheric effects, unwanted path radiance as well as unnecessary sea surface reflectance, then followed by the geometric correction to correct the distortion of the images. Subsequent, tidally correlated SBES depths were separated into two different groups, briefly the training data and testing data. Training data was utilised to determine the most appropriate tuneable constant coefficient in the depth derivation algorithms. At the end of the process, the newly constructed linear regression models were evaluated using the known measurements from the group of testing data. 


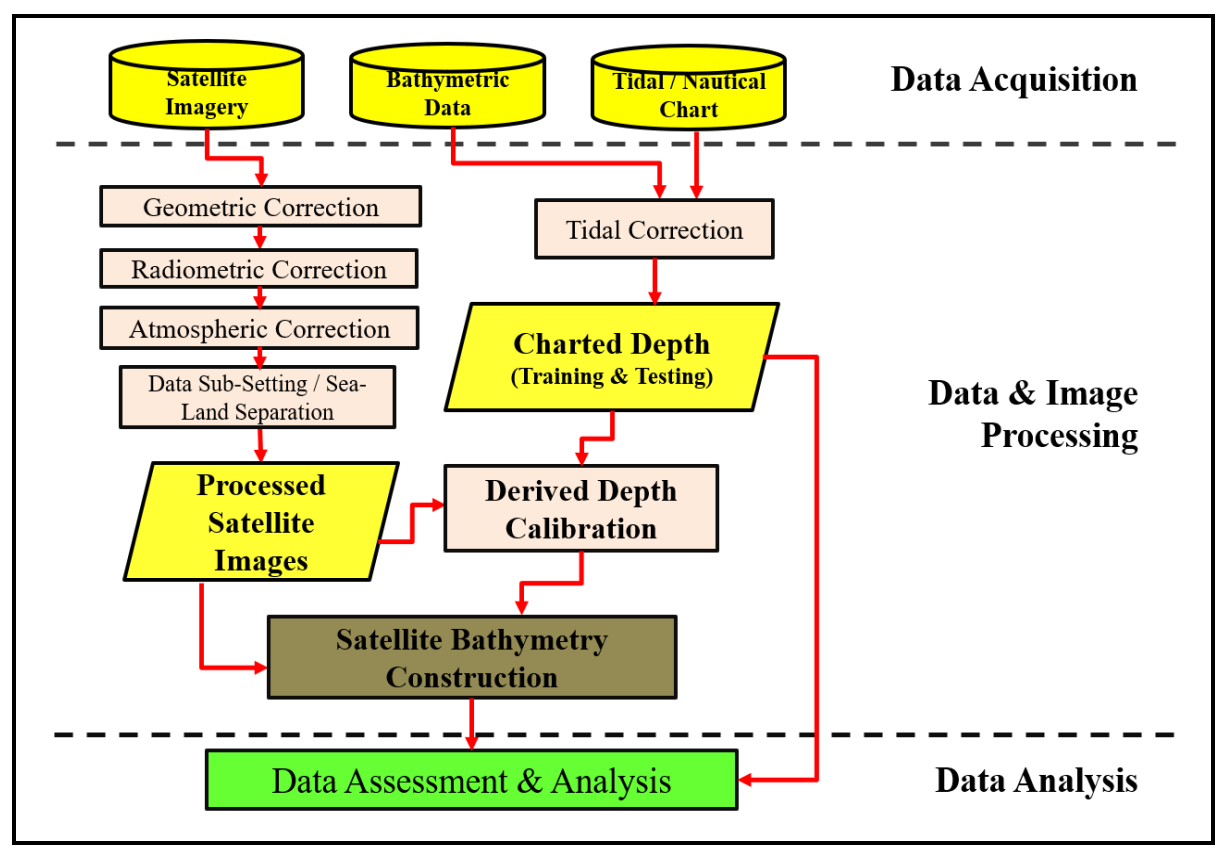

Figure 2. The overall methodology and processing stages performed in this study.

\subsection{Multispectral Satellite Imagery}

This dedicated study adopted freely downloadable Landsat- 8 multispectral images acquired on 27th June 2013 for this feasibility study. For instance, only three spectral bands, blue spectrum $(450-520 \mathrm{~nm})$, green spectrum $(530-590 \mathrm{~nm})$ and NIR spectrum $(850-880 \mathrm{~nm})$ were utilised to do this task. For instance, blue spectrum and green spectrum were used in the derivation algorithms. Thus, the near-IR (NIR) is proven to be effective in water and non-water areas separation (McFeeters, 1996; Canty, 2014). Conversely, green and NIR were utilised in the sea-land separation process, spatially filtered using Normalized Difference Water Index (NDWI).

These images were geo-referenced to the nautical chart by selecting an enough ground control points were widely scattered throughout the entire scene. Subsequently, the multispectral images were re-sampled into a relatively smaller area of which only cover the study area in order to optimize the image processing later. Image pre-processing process including radiometric correction, atmospheric correction and geometric correction were then being done order to eliminate the atmospheric effects, unwanted path radiance, unnecessary sea surface reflectance as well as the distortion of the images.

Advance and sophisticated remote sensing software such as ENVI 4.8 and ESRI ArcGIS 10.3 are proposed to be utilised in this study. Majority of the image pre-processing, processing and data generation were carried out using ENVI image processing software, while data manipulation and GIS analysis as well as map publishing were performed via ESRI ArcGIS software.

\subsection{Bathymetric Depths Measurement}

In-situ shipped-based single beam echo sounding survey (SBES) was commenced in August 2013. The accurate bathymetric depths throughout the entire study area were surveyed using a small hydrographic boat fitted with SBES synchronized with precise differential global positioning system (DGPS) positioning across the well-distributed survey lines with 5 metres interval and 25 metres line spacing.
Consequently, the tidally referenced in-situ bathymetric depths were divided into two groups. The first dataset was used to construct the depth-retrieval algorithm and another random dataset was set randomly for data assessment. A total of 1,367 check points was utilised for the final accuracy analysis at the end of the process.

\subsection{Bathymetric Depth Derivation}

This study attempted to yield the bathymetric depths over the shallow and turbid coastal region via two empirical approaches purposed by Dierssen et al. (2003) and Stumpf et al. (2003). Based on the fundamental principle of Beer-Lambert Law, both models implied the intensity of light decreases exponentially with depth, to relate the observed reflectance from the optical sensor to the water depth. Hence, the linear inversion approach can empirically derive the relationship between the pair of water-penetrating wavelengths.

\subsubsection{Dierssen Model}

Dierssen et al. (2003) has also developed a similar band-ratio concept to estimate the bathymetric depth (Z). It is presented slightly different by model the difference between observed reflectance $\log$ values. The estimated water depth is mathematically calculated from two tuneable constant coefficients $\left(\mathrm{m}_{0} \& \mathrm{~m}_{1}\right)$ and a log-difference between the observed reflectance of two consecutive bands $\left(R_{i} \& R_{j}\right)$. Equation 1 below demonstrates the Dierssen's log-ratio algorithm model:

$$
Z=m_{0} * \ln \left[\frac{n \mathrm{R}_{W}\left(\lambda_{\mathrm{i}}\right)}{\left.n \mathrm{R}_{w}\left(\lambda_{\mathrm{i}}\right)\right)}\right]+m_{1}
$$

Where,

$$
\begin{aligned}
& Z=\text { depth value from derived depth } \\
& R_{w}=\text { observed reflectance of band } i \& j \\
& m_{0}=\text { tuneable constant for ratio to depth } \\
& m_{1}=\text { offset of a depth } \\
& n=\text { constant value }
\end{aligned}
$$




\subsubsection{Stumpf Model}

Stumpf et al. (2003) has developed this simplified linear regression algorithm to determine the bathymetric depth $(\mathrm{Z})$ from two tuneable constant coefficients $\left(\mathrm{m}_{0} \& \mathrm{~m}_{1}\right)$ and a ratio of observed reflectance of two consecutive bands $\left(\mathrm{R}_{\mathrm{i}} \& \mathrm{R}_{\mathrm{j}}\right)$. It uses the division between observed reflectance log values to estimate water depth. Equation 2 below illuminates the Stumpf's band ratio algorithm model:

$$
Z=m_{0} * \frac{\ln \left(\mathrm{R}_{W}\left(\lambda_{\mathrm{i}}\right)\right)}{\ln \left(\mathrm{R}_{W}\left(\lambda_{\mathrm{j}}\right)\right)}-m_{1}
$$

Where,

$$
\begin{aligned}
& \mathrm{Z}=\text { depth value from derived depth } \\
& \mathrm{R}_{\mathrm{w}}=\text { observed reflectance of band } \mathrm{i} \& \mathrm{j} \\
& \mathrm{m}_{0}=\text { tuneable constant for ratio to depth } \\
& \mathrm{m}_{1}=\text { offset of a depth } \\
& \mathrm{n}=\text { constant value }
\end{aligned}
$$

\section{ACCURACY ASSESSMENT}

Data assessment is an important step in the determining the usability of the manipulated data or commonly known as the quality assurance as well. Indeed, it involves a comparison of the water depth (z) which estimated from imagery-derived bathymetric modal against the vertical in-situ measurement value obtained from ship-based bathymetric survey. Accuracy assessment were tabled based on descriptive statistical analysis and IHO S-44 survey standards analysis.

\subsection{Descriptive Statistical Analysis}

Precision assessment was conducted using four difference statistical approaches such as mean error, standard error, standard deviation and variance. These computational procedures are basically simple numerical comparison base on the results obtained via imagery-derived bathymetric approach against the prior known value determined via field measurement work. This study utilised the outcomes of via imagery-derived bathymetric data from both models as a predicted value and the in-situ SBES data as the reference values.

\subsection{IHO S-44 Survey Requirement}

IHO S-44 is not a specification in neither hydrographic surveys nor nautical charting. Thus, it is only used as a standard by IHO member state for the compilation of its national nautical charts. Also, this publication does not contain procedures for setting up the necessary bathymetric survey equipment for data acquisition or for processing the resultant data. It only describes the minimum orders of survey stated in IHO S-44 that are considered acceptable to produce nautical charts across the surveyed area.

Table 1. IHO S-44's TVU minimum requirements for hydrographic surveys (modified from IHO, 2008).

\begin{tabular}{lcccc}
\hline \multirow{3}{*}{ Survey Order } & \multicolumn{4}{c}{ TVU $=\sqrt{\mathrm{a}^{2}+(\mathrm{b} \mathrm{x} \mathrm{d})^{2}}$} \\
\cline { 2 - 5 } & \multicolumn{4}{c}{ For this IHO Standards Assessment, value d = } \\
\cline { 2 - 5 } & Special & $\mathbf{1 0}$ & $\mathbf{1 b}$ & $\mathbf{2}$ \\
\hline Max allowable & $\mathrm{a}=$ & $\mathrm{a}=$ & $\mathrm{a}=$ & $\mathrm{a}=$ \\
TUV (95\% & $0.25 \mathrm{~m}$ & $0.25 \mathrm{~m}$ & $0.25 \mathrm{~m}$ & $0.25 \mathrm{~m}$ \\
Confidence & $\mathrm{b}=$ & $\mathrm{b}=$ & $\mathrm{b}=$ & $\mathrm{b}=$ \\
level) & $0.0075 \mathrm{~m}$ & $0.0075 \mathrm{~m}$ & $0.0075 \mathrm{~m}$ & $0.0075 \mathrm{~m}$ \\
\hline TVU & $\pm 0.261 \mathrm{~m}$ & $\pm 0.517 \mathrm{~m}$ & $\pm 0.517 \mathrm{~m}$ & $\pm 1.026 \mathrm{~m}$ \\
\hline
\end{tabular}

Due to the variation of seabed feature and water depth, four different orders of survey are defined to cater for a range of needs. In comparison, Table 1 shows the permissible TVU for Special Order is within 0.25 metre, Order $1 \mathrm{a}$ and $1 \mathrm{~b}$ is below 0.5 metre and approximately 1.0 metre for Order 2 within 10 metres water depth).

\section{RESULT AND ANALYSIS}

This section presents the initial finding and results analysis of the imagery-derived bathymetry. Distinctly, Figure 3 to Figure 4 below illustrate the overall seabed topographical relief of the study area via digital elevation models and Table 2 and Table 3 show the statistical results and quantitative analysis of the IHO survey standard S-44 delivered by both Dierssen's and Stumpf's models.

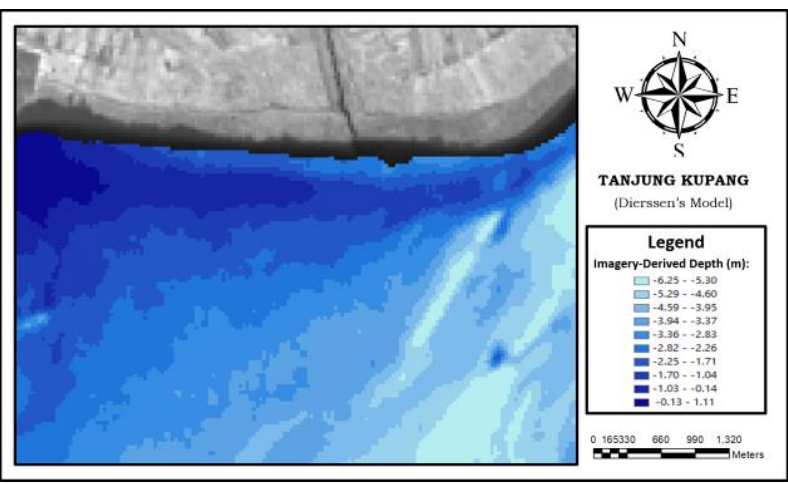

Figure 3. Imagery-derived bathymetric model from Dierssen's approach over the study area.

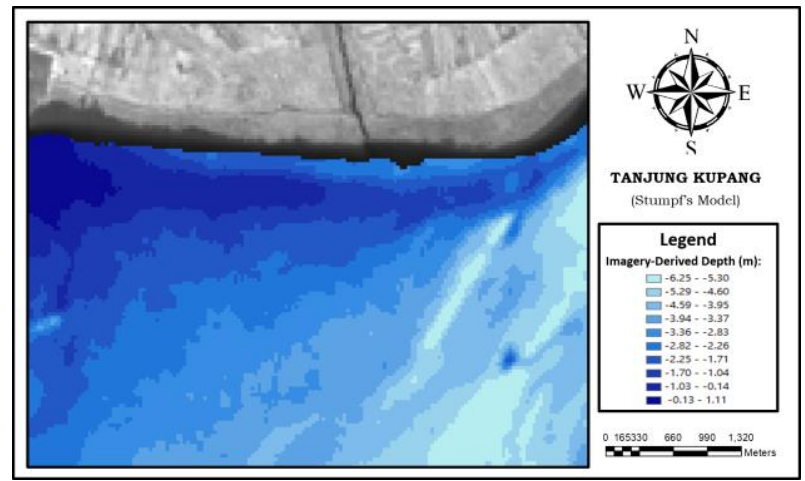

Figure 4. Imagery-derived bathymetric model from Stumpf's approach over the study area.

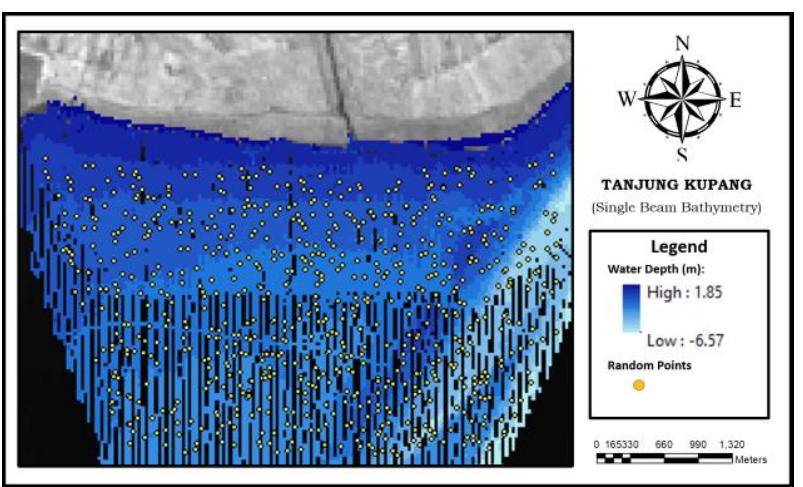

Figure 5: Location of the random points selected from the SBES data for depth validation. 
In order to quantitatively evaluate and assess the accuracy of the imagery-derived bathymetry, data quality assessment was carried out using 1,367 check points, randomly picked out from the in-situ SBES dataset (Figure 5). The overall outcomes for both Dierssen's and Stumpf's derivation models are tabled in Table 2. In comparison, the result shows significant differences in mean error where Dierssen's model produces 0.042 metres compared to 0.007 metres by Stumpf's model. However, the standard error, standard deviation and variance for both derivation models are similar. The standard deviation for Dierssen's is 0.674 metres, while Stumpf's obtains 0.673 metres. Apart from that, both models also showing similar error range of 4.782 metres for Dierssen's and 4.787 metres for Stumpf's. Generally, the outcomes indicate that both imageryderived bathymetry models provide satisfied results in this turbid water environment setting.

Table 2. Statistical results based on Dierssen's and Stumpf's models.

\begin{tabular}{lcc}
\hline \multirow{1}{*}{$\begin{array}{c}\text { Statistical } \\
\text { Analysis }\end{array}$} & \multicolumn{2}{c}{ Imagery-derived model } \\
\cline { 2 - 3 } & Dierssen Model & Stumpf Model \\
\hline Mean error & $0.042 \mathrm{~m}$ & $0.007 \mathrm{~m}$ \\
Standard error & $0.018 \mathrm{~m}$ & $0.018 \mathrm{~m}$ \\
Standard deviation & $0.674 \mathrm{~m}$ & $0.673 \mathrm{~m}$ \\
Variance & $0.455 \mathrm{~m}$ & $0.454 \mathrm{~m}$ \\
Range & $4.782 \mathrm{~m}$ & $4.787 \mathrm{~m}$ \\
Minimum & $-2.670 \mathrm{~m}$ & $-2.639 \mathrm{~m}$ \\
Maximum & $2.112 \mathrm{~m}$ & $2.148 \mathrm{~m}$ \\
\hline
\end{tabular}

Subsequently, Table 3 illustrates the total vertical uncertainty (TVU) percentage achievement of IHO S-44 survey standard based on Stumpf's model and Dierssen's model achieved here. From a total of 1,367 depth samples, Stumpf's model provides slightly higher passing rate than Dierssen's model. Stumpf's model produces a total of $1,215(88.9 \%)$ depth samples that are able to meet the minimum IHO S-44 survey requirements. Whist, 1,211 (88.5\%) depth samples out of the 1,367 depth samples from Dierssen's model are able to pass the survey standards; while, there are $152(11.1 \%)$ depth samples and 156 (11.4\%) depth samples by Stumpf's and Dierssen's yet to comply the minimum requirement established in S-44, respectively.

Table 3. The passing rate of Dierssen's and Stumpf's models based on the IHO survey standard.

\begin{tabular}{lcccc}
\hline \multirow{2}{*}{ Details } & \multicolumn{2}{c}{ Dierssen Model } & \multicolumn{2}{c}{ Stumpf Model } \\
\cline { 2 - 5 } & Sample & Percentage & Sample & Percentage \\
\hline $\begin{array}{l}\text { Sample } \\
\text { counts }\end{array}$ & 1,367 & $100 \%$ & 1,367 & $100 \%$ \\
$\begin{array}{l}\text { IHO } \\
\text { Passed }\end{array}$ & 1,211 & $88.6 \%$ & 1,215 & $88.9 \%$ \\
$\begin{array}{l}\text { IHO } \\
\text { Failed }\end{array}$ & 156 & $11.4 \%$ & 152 & $11.1 \%$ \\
$\begin{array}{l}\text { Special } \\
\text { order }\end{array}$ & 513 & $37.5 \%$ & 474 & $34.7 \%$ \\
$\begin{array}{l}\text { Order 1a } \\
\& ~ 1 b\end{array}$ & 370 & $27.1 \%$ & 395 & $28.9 \%$ \\
\begin{tabular}{l} 
Order 2 \\
\hline
\end{tabular} & 328 & $24.0 \%$ & 346 & $25.3 \%$ \\
\hline
\end{tabular}

The table above also demonstrations the quantitative analysis in regards the survey order achieved by Dierssen's and Stumpf's models in their respective minimum requirements. Although the passing rate for Stumpf's is higher, nonetheless the number of samples which successfully hit the Special Order class is only $474(34.7 \%)$ depth samples. Undeniably, Dierssen's delivers higher rate with $513(37.5 \%)$ depth samples in Special Order class. Meanwhile, another 395 (28.9\%) depth samples produce by Stumpf's and 370 (27.1\%) depth samples deliver from Dierssen's are categorised in Order 1a and 1b classes, whereas $346(25.3 \%)$ from Stumpf's and 328 (24.0\%) from Dierssen's have achieved the minimum survey Order 2 standard as stated in IHO's S-44.

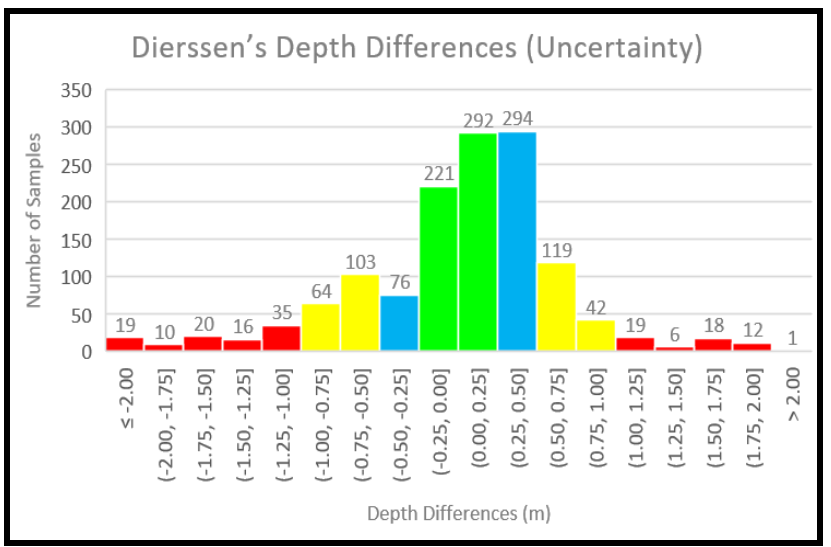

Figure 6. Distribution of depth differences and survey classes achievement from Dierssen's model.

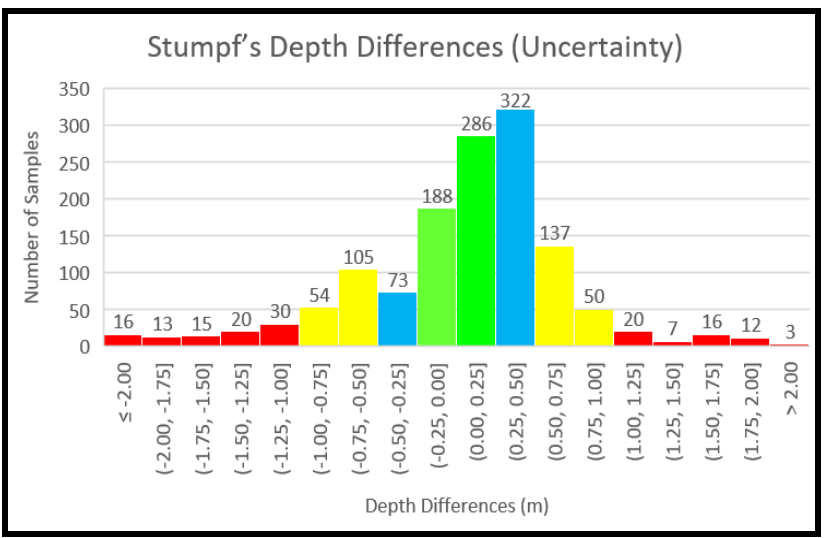

Figure 7. Distribution of depth differences and survey classes achievement from Stumpf's model.

In contrast, histogram graph in Figure 6 and Figure 7 illustrate the distribution of depth differences from both Stumpf's and Dierssen's models in regard to various survey class. The x-axis is representing the error values, while the y-axis is showing the number of samples count. The outcomes are also arranged according to IHO S-44 survey order classes in histogram graphs, respectively. The green colour indicates the number of depth samples with the highest accuracy level (Special Order); the blue and yellow bars represent depth samples that achieving Order $1 \mathrm{a} \& 1 \mathrm{~b}$ and Order 2 survey standards respectively. In contrast, those bars plotted in red are the depth sample which failed to hit the minimum TVU set in IHO S-44. 


\section{CONCLUSION}

In the completion of this study, the research goal and objectives are successfully attained. It examines the usability of satellite imagery-derived bathymetry in shallow and highly turbid waters in southwest of Johor state, Malaysia. A comparative analysis of two band ratio empirical models, namely the Dierssen's and Stumpf's models using the training data obtained from precise SBES survey. Principally, it has successfully demonstrated the level of accuracy in regard to the IHO S-44 survey requirements. Majority of the imagery-derived depths are relatively accurate, and it is capable and accomplished to meet the minimum total vertical uncertainty (TVU) survey specification.

Conversely, this study has enlightened that the imagery-derived bathymetry approach is possible to provide realistic seabed terrain profiles and three-dimensional quantitative information at the coastal and shallow water region. Although satellitederived bathymetric mapping is an innovative solution to supplement the traditional vessel-based survey techniques, yet, it can be considered as an alternative tool in determining the seabed topography over broader coastal area in Malaysia to support the marine cadastre initiative.

\section{ACKNOWLEDGEMENTS}

The authors would like to thank the Department of Survey and Mapping Malaysia, GeoCoastal Research Unit (Geospatial Imaging and Information Research Group) and Research Management Centre, Universiti Teknologi Malaysia. This research would not have been possible without their technical supports and financial aids under Research University Grant (Vote Number: R.J130000.7827.4F586).

\section{REFERENCES}

Abdullah, A., Omar, A. H., Chan, K. L., Mat Arof, X., Jamil, H., \& Teng, C. H. (2014). The development of marine cadastre conceptual model for Malaysia. Paper presented at FIG Congress 2014, Kuala Lumpur, Malaysia.

Azhari, M., Shohaime, R., Zulkifli, C., Shabudin, S., A. Majid, K., A. Fahmi, A.M., Syarifuddin, M. Z., Kamaluddin, T. \& Saiful A., S. (2017). The development of Marine Geodetic Infrastructures in East Malaysia Waters (2013-2017). Buletin GIS, Bil 2, 30-45.

Baillarin, S., Meygret, A., Dechoz, C., Petrucci, B., Lacherade, S., Tremas, T., Spoto, F. (2012). Sentinel-2 level 1 products and image processing performances. Paper presented at the Geoscience and Remote Sensing Symposium (IGARSS), 2012 IEEE International.

Bramante, J. F., Raju, D. K., \& Sin, T. M. (2013). Multispectral derivation of bathymetry in Singapore's shallow, turbid waters. International journal of remote sensing, 34(6), 20702088 .

Benny, A., \& Dawson, G. (1983). Satellite imagery as an aid to bathymetric charting in the Red Sea. The Cartographic Journal, 20(1), 5-16

Bierwirth, P., Lee, T., \& Burne, R. (1993). Shallow sea-floor reflectance and water depth derived by unmixing multispectral images. Photogrammetric Engineering and Remote Sensing;(United States), 59(3).

Dierssen, H. M., Zimmerman, R. C., Leathers, R. A., Downes, T. V., \& Davis, C. O. (2003). Ocean color remote sensing of seagrass and bathymetry in the Bahamas Banks by high- resolution airborne imagery. Limnology and Oceanography, 48(1part2), 444-455.

Doxani, G., Papadopoulou, M., Lafazani, P., Pikridas, C., \& Tsakiri-Strati, M. (2012). Shallow-water bathymetry over variable bottom types using multispectral Worldview-2 image. International Archives of the Photogrammetry, Remote Sensing and Spatial Information Sciences, 39(8), 159-164.

Gao, J. (2009). Bathymetric mapping by means of remote sensing: methods, accuracy and limitations. Progress in Physical Geography, 33(1), 103-116.

Hamylton, S. M., Hedley, J. D., \& Beaman, R. J. (2015). Derivation of high-resolution bathymetry from multispectral satellite imagery: a comparison of empirical and optimisation methods through geographical error analysis. Remote Sensing, 7(12), 16257-16273. doi:10.3390/rs71215829

Jawak, S. D., Vadlamani, S. S., \& Luis, A. J. (2015). A synoptic review on deriving bathymetry information using remote sensing technologies: models, methods and comparisons. Advances in Remote Sensing, 4(02), 147.

Jupp, D. (1988). Background and extensions to depth of penetration (DOP) mapping in shallow coastal waters. Paper presented at the Symposium on Remote Sensing of the Coastal Zone, Gold Coast, Queensland.

Lyzenga, D. R. (1978). Passive remote sensing techniques for mapping water depth and bottom features. Appl Opt, 17(3), 379383. doi:10.1364/AO.17.000379

Lyzenga, D. R., Malinas, N. R., \& Tanis, F. J. (2006). Multispectral bathymetry using a simple physically based algorithm. Ieee Transactions on Geoscience and Remote Sensing, 44(8), 2251-2259. doi:10.1109/Tgrs.2006.872909

Maritorena, S., Morel, A., \& Gentili, B. (1994). Diffuse reflectance of oceanic shallow waters: Influence of water depth and bottom albedo. Limnology and oceanography, 39(7), 16891703.

Mavraeidopoulos, A. K., Pallikaris, A., \& Oikonomou, E. (2017). Satellite derived bathymetry (SDB) and safety of navigation. The International Hydrographic Review, (17).

Nazirah, M. A. \& Abdullah, H., O. (2014). Developing boundary demarcation guideline for marine cadastre survey. Buletin Geospatial Sektor Awam. Edisi 2/2014, 21-29.

Pacheco, A., Horta, J., Loureiro, C., \& Ferreira, Ó. (2015). Retrieval of nearshore bathymetry from Landsat 8 images: a tool for coastal monitoring in shallow waters. Remote sensing of environment, 159, 102-116.

Pe'eri, S., Madore, B., Nyberg, J., Snyder, L., Parrish, C., \& Smith, S. (2016). Identifying bathymetric differences over alaska's north slope using a satellite-derived bathymetry multitemporal approach. Journal of Coastal Research, 56-63. doi:10.2112/Si76-006 
Pe'eri, S., Parrish, C., Azuike, C., Alexander, L., \& Armstrong, A. (2014). Satellite remote sensing as a reconnaissance tool for assessing nautical chart adequacy and completeness. Marine Geodesy, 37(3), 293-314. doi:10.1080/01490419.2014.902880

Philpot, W., Davis, C. O., Bissett, W. P., Mobley, C. D., Kohler, D. D., Lee, Z.,Trowbridge, J. (2004). Bottom characterization from hyperspectral image data. Oceanography, 17(2), 76-85.

Sam, L., Prusty, G., \& Gahlot, N. (2017). Evaluation of optical remote sensing-based shallow water bathymetry for recursive mapping. Geocarto International, 1-17.

Said, N. M., Mahmud, M. R., \& Hasan, R. C. (2017). Satellitederived bathymetry: Accuracy assessment on depths derivation algorithm for shallow water area. International Archives of the Photogrammetry, Remote Sensing \& Spatial Information Sciences, 42.

Said, N. M., Mahmud, M. R., \& Hasan, R. C. (2018, June). Evaluating satellite-derived bathymetry accuracy from Sentinel2A high-resolution multispectral imageries for shallow water hydrographic mapping. In IOP Conference Series: Earth and Environmental Science (Vol. 169, No. 1, p. 012069). IOP Publishing.

Sánchez-Carnero, N., Ojeda-Zujar, J., Rodríguez-Pérez, D., \& Marquez-Perez, J. (2014). Assessment of different models for bathymetry calculation using SPOT multispectral images in a high-turbidity area: the mouth of the Guadiana Estuary. International journal of remote sensing, 35(2), 493-514.

Stumpf, R. P., Holderied, K., \& Sinclair, M. (2003). Determination of water depth with high-resolution satellite imagery over variable bottom types. Limnology and Oceanography, 48(1), 547-556.

Su, H. B., Liu, H. X., \& Heyman, W. D. (2008). Automated derivation of bathymetric information from multi-spectral satellite imagery using a non-linear inversion model. Marine Geodesy, 31(4), 281-298. doi:Pii 906372417

$10.1080 / 01490410802466652$

Tang, K.K.W., \& Pradhan, B. (2015). Converting digital number into bathymetric depth: A case study over coastal and shallow water of Langkawi Island, Malaysia. Paper presented at the FIG Working Week 2015, Sofia, Balgeria.

Zheng, G., Chen, F., \& Shen, Y. (2017). Detecting the water depth of the South China Sea reef area from WorldView-2 satellite imagery. Earth Science Informatics, 10(3), 331-337. 